\title{
Collaborative EFFORTS ARE NEEDED tO IMPROVE USE OF INFLUENZA IMMUNISATION IN EUROPE
}

\author{
E Hak (e.hak@umcutrecht.nl) 1 \\ 1. University Medical Center Utrecht, Julius Center for Health Sciences and Primary Care,
}

This week's special issue of Eurosurveillance highlights various aspects and challenges related to the prevention of influenza by vaccination. Influenza is among the infectious diseases with the highest incidence and associated serious morbidity and mortality that can be prevented by vaccination. In the article of the Vaccine European New Integrated Collaboration Effort (VENICE), investigators report details of vaccine coverage among different segments of the target population in the European Union (EU) and European Economic Area (EEA) Member States. Among elderly persons, only the Netherlands succeeded in reaching vaccine uptake levels above $75 \%$, the 2010 target of the World Health Organization (WHO); twelve countries reported $50 \%$ to $75 \%$ coverage, nine countries were even below the 2006 target of $50 \%$ and seven countries could not report any data. Importantly, vaccine uptake among clinical risk groups and health care workers was even lower. In a detailed report from France, F. Rance et al. reported that only $17 \%$ of asthmatic children were vaccinated against influenza. Furthermore, on behalf of the European Vaccine Manufacturers, M. Rodriquez de Azero et al. showed that the vaccine doses per capita only marginally increased from $17 \%$ to $20 \%$ in the years 2003 to 2006 . So how can we be more successful in the prevention of influenza?

In the United States (US), it has been estimated that on average 51,000 persons die from influenza during epidemics each year [1]. Based mostly on figures from the US, most of the influenza burden is among persons with risk-elevating medical conditions such as chronic respiratory, cardio- or cerebrovascular or renal disease, diabetes and immunodeficiency, and among infants, older adults and residents of long-term health care settings [2]. Similar epidemiological studies in Europe could be of use to convince local politicians about the need to reduce the burden among these vulnerable groups. The Health Council of the Netherlands, for example, decided to lower the age threshold for vaccination from 65 to 60 years in 2007 based on the large excess in the number of primary care visits, hospitalisations and mortality among the healthy aged 60 to 64 years during epidemics [3]. Indeed, the lack of data on influenza burden at the more severe end of the clinical spectrum in many European countries probably contributes to the large variations in vaccine uptake reported to the VENICE investigators.

The success of vaccination is largely determined by its impact on disease burden in the target group when applied in practice. Recently, the effects of influenza vaccination on the incidence of pneumonia and mortality from all causes among the elderly have been debated. In the US, the influenza-associated mortality among elderly persons has not declined over the last decades despite increase in vaccine uptake, whereas in the Netherlands a clear reduction in mortality seems to have taken place after the national influenza vaccination campaign $[4,5]$. These contrasting findings have led to much discussion mainly about the potential for confounding in nonrandomised observational studies, which may have had an impact on the validity of reported effect estimates so far.

An important feature of randomisation is that it removes all kinds of biases; hence randomised controlled trials (RCTs) are considered the paradigm to study vaccine effects. Many RCTs have been conducted among healthy adults showing that vaccination prevented a considerable part of proven influenza infections [6]. Also, a landmark trial among elderly persons demonstrated a $50 \%$ reduction in influenza illness [7]. However, such trials with death as an outcome are unlikely to be carried out in Europe. Influenza vaccines are currently recommended for a wide variety of patients, and serious outcomes such as deaths due to infection are infrequent. Thus the design of an RCT would require very large representative study samples. Also the vaccines can only be effective when patients are actually exposed to the virus and the vaccine matches circulating strains neither of which can be predicted. Finally, placebo-controlled influenza vaccine trials in the elderly and most high-risk groups are usually considered unethical in Europe, since as the VENICE survey found vaccinating these persons is recommended in immunisation guidelines in most countries.

Non-randomised case-control or cohort vaccine effectiveness studies are feasible alternatives to RCTs. They have the advantages of applicability in different patient populations, timeliness, reduction of costs, and increased feasibility. However, in observational studies the selection of patients for vaccination is influenced by their risk profile, which may lead to 'confounding by indication'. Typically, the vaccinated group comprises patients with more severe disease or higher risk than the unvaccinated group. Crude, uncontrolled, estimates of the association between vaccination and outcome in such studies, therefore, lead to an underestimation of vaccine effectiveness. Conversely, if refusal of vaccination is typically associated with low functional health status, the unvaccinated group may comprise persons with a worse prognosis than the control group. This so-called 'healthy user bias' will lead to an overestimation of the true vaccine effectiveness. Both types of biases can be present in influenza vaccine studies and it is therefore a challenge to the investigator to prevent and adjust for the confounding in the design of data collection and analysis, and, if possible, to quantify its potential magnitude [8-10].

The report by M. Valenciano et al. provides the reader with a very complete overview of the observational studies that were conducted 
in the EU Member States and the potential for confounding bias. The authors suggested that in designing studies aimed at measuring accurately and in a timely manner the vaccine effectiveness in Member States, based on an extensive literature review and expert meetings, case-control and cohort studies should be set up, and in the case-control study the main outcome should be laboratoryconfirmed influenza. In the same paper much attention has been given to measure as many potential confounding factors as possible. To quantify potential unmeasured bias it was suggested to also conduct cohort studies during pre- and post-influenza seasons. However, pre-influenza seasons are invalid reference seasons because influenza can still be present. Also, terminal patients may be included in cohorts evaluating the pre-influenza season, which can also induce selection bias such that vaccine effects are overestimated, because these patients may refrain from vaccination. These limitations notwithstanding and although more methods are available to quantify the potential impact of unmeasured confounding, the proposed studies are essential attempts to maintain confidence in the benefit of the vaccine programme.

Furthermore, country-specific data on influenza burden and European estimates of the effectiveness of vaccination are needed to estimate the cost-effectiveness of the vaccination programmes. Based on data from the Dutch PRISMA nested case-control study [11] and the abovementioned excess study [3], it was estimated that the vaccination programme in the Netherlands certainly resulted in saving money and concluded that it was cost-effective to vaccinate all adults aged between 60 and 64 years [12]. Consequently, the Dutch ministry of health decided to extend the vaccination programme to the lower age limit of 60 years. However, since the use of resources is different from country to country, such analysis should be initiated in each country or undertaken at an EU level to support the actual implementation of the vaccination programme.

Alarming reports of sudden cardiac failure after influenza vaccination in Israel [13] and the Netherlands [14] during the 2007 influenza season had a negative impact on vaccine acceptance, even though national surveillance data indicated that these few fatal cases could be explained by chance alone and no causative relationship was found. Undoubtedly, more potent adjuvanted vaccines will replace current conventional vaccines in the next few years and many countries are currently considering stockpiling (pre)pandemic vaccines for use on a large scale in a pandemic. For these reasons, a carefully developed risk management plan is necessary to be able to prevent potential harm during mass vaccination campaigns [15].

Finally, it needs to be acknowledged that the development of immunisation recommendations even when supported by, preferably local, evidence does not necessarily lead to acceptance of the vaccine by the public. Various factors determine the uptake of vaccination and educational programmes should be based on evidence from surveys that attempt to predict vaccine acceptance according to health behavioural and implementation models [16-19]. National commitment by government and professionals is crucial and this partly explains the successful performance of countries with better vaccination coverage. Such commitment is now needed at an EU level so that all countries can achieve such results. To conclude, collaborative action involving experts from the fields of public health, clinical epidemiology, psychology and health economy is needed to set up a European-wide infrastructure for studies on the epidemiology, (cost-)effectiveness, risk management and acceptance to further improve confidence and coverage in the influenza immunisation programmes. Reports published in this issue of Eurosurveillance provide useful guidance how to proceed.

\section{References}

1. Thompson WW, Shay DK, Weintraub E, Brammer L, Cox N, Anderson LJ, Fukuda K. Mortality associated with influenza and respiratory syncytial virus in the United States. JAMA. 2003 Jan 8;289(2):179-86.

2. Fiore AE, Shay DK, Broder K, Iskander JK, Uyeki TM, Mootrey G, et al.; Centers for Disease Control and Prevention (CDC); Advisory Committee on Immunization Practices (ACIP). Prevention and control of influenza: recommendations of the Advisory Committee on Immunization Practices (ACIP), 2008. MMWR Recomm Rep. 2008 Aug 8;57(RR-7):1-60.

3. Jansen AG, Sanders EA, Hoes AW, van Loon AM, Hak E. Influenza- and respiratory syncytial virus-associated mortality and hospitalisations. Eur Respir J. 2007 Dec;30(6):1158-66. Epub 2007 Aug 22. Erratum in: Eur Respir J. 2008 Mar;31(3):691.

4. Simonsen L, Taylor RJ, Viboud C, Miller MA, Jackson LA. Mortality benefits of influenza vaccination in elderly people: an ongoing controversy. Lancet Infect Dis. 2007 Oct;7(10):658-66. Review.

5. Jansen AG, Sanders EA, Nichol KL, van Loon AM, Hoes AW, Hak E. Decline in influenza-associated mortality among Dutch elderly following the introduction of a nationwide vaccination programme. Vaccine. 2008 Aug 21.

6. Jefferson To, Rivetti D, Di Pietrantonj C, Rivetti A, Demicheli V. Vaccines for preventing influenza in healthy adults. Cochrane Database Syst Rev. 2007 Apr 18;(2):CD001269. Review.

7. Govaert TM, Thijs CT, Masurel N, Sprenger MJ, Dinant GJ, Knottnerus JA. The efficacy of influenza vaccination in elderly individuals. A randomized doubleblind placebo-controlled trial. JAMA. 1994 Dec 7;272(21):1661-5.

8. Groenwold RH, Hak E, Hoes AW. Quantitative assessment of unobserved confounding is mandatory in nonrandomized intervention studies. J Clin Epidemiol. 2008 Jul 9.

9. Lin DY, Psaty BM, Kronmal RA. Assessing the sensitivity of regression results to unmeasured confounders in observational studies. Biometrics. 1998 Sep;54(3):948-63.

10. Nichol KL, Nordin JD, Nelson DB, Mullooly JP, Hak E. Effectiveness of influenza vaccine in the community-dwelling elderly. $N$ Engl J Med. 2007 Oct 4;357(14):1373-81.

11. Hak E, Buskens E, van Essen GA, de Bakker DH, Grobbee DE, Tacken MA, van Hout $B A$, Verheij TJ. Clinical effectiveness of influenza vaccination in persons younger than 65 years with high-risk medical conditions: the PRISMA study. Arch Intern Med. 2005 Feb 14;165(3):274-80.

12. Health Council of The Netherlands. Influenza vaccination: revision of the indication. The Hague: Health Council of The Netherlands, 2007; publication no. 2007/09 [with summary in English]

13. Kokia ES, Silverman BG, Green M, Kedem H, Guindy M, Shemer J. Deaths following influenza vaccination--background mortality or causal connection? Vaccine. 2007 Dec 12;25(51):8557-61.

14. van der Sande MA, van Asten L, Straus SM, Schim van der Loeff MF, Wallinga J, Conyn-van Spaendonck MA. Sudden deaths following influenza vaccination: can this be expected? Vaccine. 2008 Jan 17;26(3):379-82.

15. Labadie J, van Grootheest AC. [Adverse events following vaccination reported to the Netherlands Pharmacovigilance Center Lareb in 2004-2006] Ned Tijdsch Geneeskd. 2007 Dec 8;151(49):2738-42. Dutch.

16. Johnson DR, Nichol KL, Lipczynski K. Barriers to adult immunization. Am J Med. 2008 Jul;121(7 Suppl 2):S28-35.

17. Van den Dool C, Van Strien AM, den Akker IL, Bonten MJ, Sanders EA, Hak E. Attitude of Dutch hospital personnel towards influenza vaccination. Vaccine. 2008 Mar 4;26(10):1297-302.

18. Looijmans-van den Akker I, van den Heuvel PM, Verheij TJ, van Delden JJ, van Essen GA, Hak E. No intention to comply with influenza and pneumococcal vaccination: behavioural determinants among smokers and non-smokers. Prev Med. 2007 Nov;45(5):380-5.

19. Looijmans-van den Akker I, van Delden JJ, Hak E. Uptake of influenza vaccination in Dutch nursing home personnel following national recommendations. J Am Geriatr Soc. 2007 Sep;55(9):1486-7.

This article was published on 23 October 2008.

Citation style for this article: Hak E. Collaborative efforts are needed to improve use of influenza immunisation in Europe. Euro Surveill. 2008:13(43):pij=19011. Available online: http://www.eurosurveillance.org/ViewArticle.aspx?ArticleId=19011 